the order of accuracy attainable in comparing sources of different colour. The final day at Birmingham was devoted to a day-trip to Stratford-on-Avon, after which members proceeded to Cambridge.

The meeting at Cambridge was generally regarded as one of the most successful parts of the Congress, and was well attended. In the course of the visit, there were trips to Ely and Peterborough (the latter an evening visit so that the artificial lighting of the cathedral might be inspected) and an address on "The Light of the Stars" by Sir Arthur Eddington. There was also a comprehensive demonstration of anti-dazzle devices by the Royal Automobile Club, which was instructive in demonstrating recent progress in this field. A considerable amount of work was done, sessions being devoted to such matters as street lighting, daylight illumination, nomenclature, definitions and symbols, photometric test-plates, traffic signals, glare, motor-car headlights, photometric accuracy, aviation lighting, heterochromatic photometry, the lighting of schools and factories, etc.-- on most of which reports reviewing progress and, in some cases, leading to definite recommendations were presented.

Amongst the numerous points on which decisions were taken the following may be noted. It was agreed that in visual photometry the most accurate measurements are possible with illuminations between 5 lux and 20 lux, and that in the laboratory a mean error of an order not exceeding 0.25 per cent is possible, whilst in commercial work a limit of 3 per cent may be attained. In regard to daylight, the 0.2 per cent daylight factor (at present applied in Great Britain legally in connexion with Ancient Lights cases) was regarded as a minimum-which would be definitely inadequate in the case of work involving much visual discrimination. It was further agreed that a committee should be set up to consider the standardisation of artificial daylight. The Section on Lighting Education formulated many recommendations, such as the inclusion of instruction in illumination at postprimary schools and in architectural colleges, and the organisation of at least one full specialised course in illuminating engineering in each country. In connexion with headlights, the distinction between the 'driving beam' and the 'passing beam' was recognised, and steps to limit glare and ensure adequate illumination were proposed. It is interesting to observe a consensus of opinion that coloured beams of light are of no material advantage in fogs.

Other resolutions related to traffic control and street lighting, a desire for fuller data in regard to the influence of traffic signals on road accidents being expressed. In connexion with street lighting, it was recommended that, in order to facilitate international comparisons, contributors should give $(a)$ a description of the fitting, (b) particulars of spacing, and (c) both average and minimum illumination.

An invitation for the next meeting of the International Illumination Congress to take place in Germany was accepted for 1934, when the president will be Dr. A. R. Meyer.

\title{
International Congress for the Testing of Materials.
}

TWHE New International Association for Testing 1 Materials held its first congress at Zurich on Sept. 6-11. Although this was the first congress of the New International Association, eleven international congresses on the testing of materials have been held in the past. Ten of these were held by the original International Association which was formed more than thirty years ago under the auspices of Tetmayer and Bauschinger. This Association was broken up during the War, but a new International Association was formed at a congress in Amsterdam which had been arranged in September 1927 by the Dutch Association for Testing Materials. The new Association, although it is continuing the most valuable work of its predecessor, differs from it in many important respects, particularly by being a much simpler organisation, which avoids so far as possible the formation of numerous permanent committees, and also by entirely eliminating all questions of international standard specifications.

The Congress at Zurich was presided over by Prof. A. Mesnager, of the Conservatoire National des Arts et Métiers, Paris, and its work was carried out in four sections, namely : $(A)$ Metals, under the presidency of Dr. W. Rosenhain, London; $(B)$ Inorganic Materials, stone, cement, concrete, etc., under the presidency of Prof. M. Roš, director of the Swiss Federal Testing Laboratory at Zurich; $(C)$ Organic Materials, bitumen, paints, rubber, etc., under the presidency of Prof. Roos af Hjelmsäter, Stockholm ; $(D)$ Questions of General Importance, under the presidency of Prof. Goerens, of Messrs. Krupp. Most of these sections held five sessions, each occupying a whole morming or afternoon and each devoted to the discussion of a single selected subject, upon which a number of reports by experts of international standing were first presented in brief abstract, a general discussion following. The reports were of a very high order of interest and importance, and particularly good dis- cussions took place. The work of the Congress was, throughout, animated by the spirit of international co-operation and friendship, and by the desire of all those taking part to further the common cause of improving our methods of testing and of advancing our knowledge of the properties of materials, upon which satisfactory methods of testing must be founded.

In Section $A$, the subjects discussed were cast iron, notched-bar impact testing, fatigue, materials at high temperatures, and the progress of metallography. In regard to cast iron, considerable divergence of opinion and practice appears to exist, particularly between the French engineers and those of other countries. As a result of the discussion, however, the president of the Section hopes to issue a brief summary acceptable to all those who took part. Such a summary should serve as a guide to those bodies whose business it is to deal with standardisation, both national and international. The same applies to the notched-bar impact test, where the adoption of a standard test piece affording comparable results in different countries is particularly desirable.

In Section $B$, the importance of geological factors in the testing of stone was discussed, and new data on the resistance of road-building materials to shock were presented. Cement testing, concrete testing, and the testing of reinforced concrete were also discussed at length, the latter subject presenting a series of particu. larly important problems.

Section $C$ dealt with the problems of asphalt or bitumen, which has attained so much importance in regard to road construction, and special attention was devoted to the question of nomenclature, upon which international agreement appears to be highly necessary. In regard to the testing of timber, the decisive importance of moisture content on all strength properties was emphasised; it is suggested that con. sideration of this factor clears up the existing difficul ties in the relations between compression, bending, and

No. 3232, VoL. 128] 
tensile strength. Questions of ageing of materials such as oils, textiles, synthetic resins, and rubber were also discussed, the importance of temperature, oxygen, and light being considered. A discussion on viscosity brought out a consensus of opinion that the "poise" should be adopted as the unit of dynamic viscosity and the 'stokes' as the unit of kinematic viscosity. Tables for the conversion of data expressed in other units to this system are to be prepared. Considerable attention was also paid to the question of solid fuels, particularly with regard to the sampling of coal.

In Section $D$, the subjects treated related to the determination of grain size in powdery materials, the calibration of testing machines, and the general conceptions implied by the terms 'elasticity', 'plasticity', 'toughness', and 'brittleness'. A general discussion on the latter question proved of particular interest.

At the opening meeting of the Congress, the delegates of some thirty-four nations made brief speeches in reply to the opening addresses of the president and the representatives of the Swiss Federal Government and of the Canton and City of Zurich; they paid tribute to the early work of Tetmayer at Zurich and to that of his present successor, Prof. Roš, for the great work he had done in the successful organisation of the Congress in his capacity of general secretary of the International Association. Great Britain was represented by Sir Henry Fowler and Dr. W. Rosenhain. The latter, as representative of Great Britain on the Permanent Committee of the International Association, was the bearer of an invitation from the British Committee to the International Association to hold its next Congress in London in 1935. At the final plenary session of the Congress, this invitation was accepted, and Dr. Rosenhain was elected as the next president of the New International Association. It is hoped that the sectional presidencies will be filled as follows : $(B)$ Dr. Barta, Czechoslovakia ; $(C)$ Prof. Suenson, Denmark ; (D) Dr. G. K. Burgess, director of the Bureau of Standards, U.S.A. The presidency of Section $A$ has not yet been filled, but it is hoped that it may be accepted by Prof. Goerens, of Essen.

It is interesting to note that on this occasion, although British participation was not very numeroussome five hundred members attended the Congress, and of these not more than twenty were British-yet the British representatives took a very active and important part in the work of the Congress, and the importance of their work and influence was fully appreciated and is likely to prove of value to British technical and industrial prestige throughout the world.

\section{Association of Special Libraries and Information Bureaux.}

$\mathrm{T}^{\mathrm{H}}$ E eighth annual Conference of the Association of Special Libraries and Information Bureaux was held at Lady Margaret Hall, Oxford, on Sept. 18-21, and the attendance and papers presented at the Conference, as well as the discussions, manifested a growing appreciation of the value of such a clearing house for multiplying sources of specialised information both in science and industry. Anxiety regarding the future of the Association in view of its unsatis. factory financial situation, which Dr. R. S. Hutton emphasised at the annual general meeting, appeared indeed rather to intensify the sense of the value of the Association's work, and several speakers at this and other sessions urged the importance of defining more clearly the functions of A.S.L.I.B. so as to prevent undue diffusion of effort.

The need for some such central index and pointer to sources of special information was repeatedly emphasised, and discussions on the Library and Information Departments of the Royal Institute of International Affairs and on the League of Nations and the International Labour Office as sources of information for economic affairs ultimately issued in a resolution urging the Council to promote the effective organisation of some such central index or means of co-ordination. An offer to provide clerical assistance in such a move was made by Mr. B. M. Headicar, of the London School of Economics, and the experience of the groups established during the year in Yorkshire and in Lancashire and Cheshire has indicated the value of local co-operation and contact, as well as central organisation in promoting the rapid exchange of information between members to their mutual advantage.

Special interest was supplied to the opening session of the Conference by a paper in which Prof. A. M. Carr-Saunders analysed some of the problems of professionalism, including professional training and the restriction of entry to professions to which allusion has recently been made in NATURE. State control or interference in professional matters is largely determined by the necessity of maintaining a reasonable standard of competence as in law and medicine, or of securing the public safety as in regulations relating to marine officers. When the contact between the members of a profession and the public is only indirect, as in certain professions the legal restriction of which has been attempted in recent years, it is much more difficult to establish a case for State regulation. The growth of specialisation makes the question of competence much more difficult, and even in the medical profession the question of dealing with or proving incompetence has not been entirely solved.

Prof. Carr-Saunders, pointing out the dangers inherent in registration and professionalism, suggested that as an alternative to multiplication of selfgoverning professional organisations a wider use might be made of powers obtained under and administered through the Privy Council as a means of maintaining high professional standards. Referring to professional training, Prof. Carr-Saunders stated that in the modern tendency for professional training to be given at the universities, the universities are reverting to their original functions. The development of the Association of Special Libraries and Information Bureaux is an indication of the importance of these questions in regard to librarians and the competent handling of information.

In the session over which Sir Charles Sherrington presided, Mr. E. N. Simon directed attention to the valuable and original scientific information which is now contained in the publications of industrial firms and frequently only available in such literature. In recent years the character of such publications has totally changed, and technical service literature now contains an increasing amount of information and data of direct practical, scientific, and technical value to scientific workers in general and not to research workers in industry alone. Other speakers who confirmed this view directed attention to the difficulty even in industry of rendering such information readily accessible, and the importance of co-operation in making it known, whether through the offices of A.S.L.I.B. or otherwise, was evident.

Sir Frederic Nathan's paper on international abstracting and indexing of scientific and technical literature was a further presentation of the scheme he outlined last year before the Chemical Engineering

No. 3232 , VoL. 128] 